\title{
Family conflict and slow growth
}

\author{
Scott M Montgomery, Mel J Bartley, Richard G Wilkinson
}

University

Department of

Medicine, Royal Free

Hospital School of

Medicine, London

S M Montgomery

Department of

Epidemiology and

Public Health,

University College

London Medical

School

M J Bartley

Trafford Centre for Medical Research,

University of Sussex, Brighton

R G Wilkinson

Correspondence to:

Dr Montgomery.

Accepted 8 July 1997

\begin{abstract}
Aims-Having previously observed that slow growth in childhood is associated with subsequent labour market disadvantage, an attempt was made to determine whether family conflict is associated with slow growth to age 7 years, independently of material disadvantage.

Methods-A total of 6574 children born between 3 and 9 March 1958 who were members of the British National Child Development Study were used in these analyses. Slow growth at age 7 years was indicated by short stature defined as the lowest fifth of the height distribution. In multivariate analysis, adjustment was made for fully attained adult height as a measure of genetically predetermined height.

Results-A total of $31.1 \%$ of children who had experienced family conflict were of short stature compared with $20.2 \%$ of those who had not, representing relative odds of 1.79 (95\% confidence interval (CI) 1.39 to 2.30). After adjustment for social class, crowding, sex, and predetermined height, the relative odds were slightly reduced to $1.62(95 \%$ CI 1.18 to 2.23$)$. A total of $44.0 \%$ of children from the most crowded households were of short stature compared with $16.4 \%$ of those from the least crowded. The unadjusted relative odds were 3.99 (95\% CI 2.94 to 5.41) and after adjustment for the potential confounding variables they were 3.07 (95\% CI 2.08 to 4.51 ). Low social class was also a risk for short stature at age 7 years, but this was not statistically significant after adjustment for the other confounding factors.
\end{abstract}

Conclusions-Family conflict during childhood was independently associated with slow growth to age 7 years.

(Arch Dis Child 1997;77:326-330)

Keywords: growth; family conflict; stress; development

There have been previous reports of psychosocial and material influences on height and growth. ${ }^{1-3}$ We decided to investigate evidence of the effect of psychosocial and material circumstances on slow growth in childhood among members of the National Child Development Study (NCDS): the 1958 British birth cohort.

Longevity and upward social mobility are strongly and independently related to height and height appears to be an important indicator of social variation in health. ${ }^{4}$ The strength of the relation between height and social mobility led to the heights of civil servants in the Whitehall Study being more closely related to achieved occupational grade than to their social class of origin. ${ }^{5}$ It was once widely assumed that findings such as these indicated that height was a marker for some physiological advantage and also perhaps that tall people were upwardly mobile because of a human tendency to be impressed by stature. These interpretations are unlikely to represent a full explanation, however, as it has been shown that unemployment in early adulthood, which is a good marker for general labour market disadvantage, was much more closely related to slowed growth to age 7 years than to fully attained adult height. ${ }^{6}$ This suggests that some feature of the childhood environment may influence both early growth rate and labour market success.

If slow growth is identified as an indicator of psychosocial stress caused by family conflict, this may provide more information about the processes by which more health risks are accumulated across the life course among those who experience adversity in childhood. As growth reflects underlying metabolic activity, slow growth could also be a marker for processes that are themselves potentially damaging for future mental and physical health.

\section{Subjects and methods}

SUBJECTS

The data used were taken from the NCDS, ${ }^{7-10}$ a continuing national longitudinal study of approximately 16000 subjects living in Great Britain who were born between 3 and 9 March 1958. There have been six data collection sweeps at birth and at ages $7,11,16,23$, and 33 years. As a result of sample attrition and the exclusion of subjects with incomplete data, these analyses were limited to 3169 male and 3405 female subjects. The cohort has nevertheless remained largely representative, although the most disadvantaged groups are under-represented. ${ }^{11}$

\section{MEASURES}

Height at age 7 years was measured by school doctors to the nearest inch. The bottom fifth of the height distribution (estimated separately for boys and girls), containing the shortest children, was used as a binary variable in the analysis. The shortest fifth was chosen as a possible indicator of slowed growth for two reasons: firstly, because a similar measure used in previous analyses ${ }^{6}$ clearly identified a group who would subsequently experience a significantly increased risk of labour market disadvantage in adult life, even after adjustment for the relevant potential confounding factors; 
and, secondly, by focusing on the shortest fifth of children we are attempting to show that we have defined a group that may be readily identified as containing a higher proportion of children who have experienced psychosocial stress. Height at age 33 years was measured to the nearest centimetre by social research interviewers using portable stadiometers. Height at age 33 years was used as a continuous variable. Where heights were defined as a group variable, the proportions in each group vary slightly as a function of rounding bias and sex standardisation.

A binary measure of family conflict was taken from a questionnaire completed by the cohort member's health visitor at age 7 years. The health visitor reported family difficulties due to domestic tension, divorce, separation, or desertion. This was based on the health visitor's previous knowledge of the family, usually through involvement of the family with statutory or voluntary bodies such as the Marriage Guidance Council.

The Registrar General's social class classification based on the father's occupation when the cohort member was 7 years of age was used to indicate socioeconomic conditions. Subjects were excluded where the father's occupation was not recorded, including where the father was not resident in the household. Crowding was used as an indicator of social disadvantage $^{12}$ to provide a more accurate measure of the standard of living ${ }^{13}$ than social class alone. The measure of crowding was based on the number of people per room, excluding kitchens and bathrooms, when the cohort members were aged 7 years. This was divided into four categories: up to one person per room; more than one and up to one and a half people per room; more than one and a half and up to two people per room; and more than two people per room. The last category represents the greatest relative disadvantage.

\section{STATISTICAL METHODS}

The relation between family conflict, family circumstances, and growth to age 7 years was examined by cross tabulation (statistical significance was established using the $\chi^{2}$ test for trend) and multiple logistic regression. Height at age 7 years was divided at the bottom fifth to form a binary dependent variable. We adjusted for height at 33 years, modelled as a linear vari-

Table 1 Height distribution at age 7 years by family conflict. Values are percentages

\begin{tabular}{lllllll}
\hline \multirow{2}{*}{ Family conflict } & $\begin{array}{l}\text { No of children } \\
(n=6574)\end{array}$ & \multicolumn{2}{l}{ Height distribution (fifths) } \\
\cline { 3 - 7 } & 1 (shortest) & 2 & 3 & 4 & 5 (tallest) \\
\hline No & 6275 & 20.2 & 14.2 & 28.2 & 16.6 & 20.9 \\
Yes & 299 & 31.1 & 13.7 & 28.4 & 12.4 & 14.4 \\
\hline
\end{tabular}

$\mathrm{p}<0.0005$.

Table 2 Height distribution at age 33 years by family conflict. Values are percentages

\begin{tabular}{lllllll}
\hline \multirow{2}{*}{ Family conflict } & $\begin{array}{l}\text { No of children } \\
(n=6574)\end{array}$ & \multicolumn{5}{l}{ Height distribution (fifths) } \\
\cline { 3 - 7 } & 1 (shortest) & 2 & 3 & 4 & 5 (tallest) \\
\hline No & 6275 & 18.9 & 21.4 & 18.6 & 21.9 & 19.2 \\
Yes & 299 & 23.7 & 19.7 & 19.1 & 22.7 & 14.7
\end{tabular}

$\mathrm{p}<0.051$. able, in the multiple logistic regression model. This model was also adjusted for social class, crowding, and sex. All independent variables, with the exception of adult height at age 33 years, were modelled using binary dummies. Subjects with incomplete data were excluded from the analysis. All analyses were conducted using SPSS. ${ }^{14}$

\section{Results}

A total of $299(4.5 \%)$ cohort members had been exposed to family conflict by age 7 years as indicated by the health visitor's report. The height range at age 7 years for boys in the shortest fifth was $1.02-1.17 \mathrm{~m}$, with a mean of $1.15 \mathrm{~m}$. The range for other boys was $1.19-1.52 \mathrm{~m}$, with a mean of $1.25 \mathrm{~m}$. For short girls the range was $0.99-1.17 \mathrm{~m}$, with a mean of $1.14 \mathrm{~m}$; for the taller girls the range was 1.19 $1.55 \mathrm{~m}$ with a mean of $1.24 \mathrm{~m}$. A total of 1358 boys and girls were in the short stature group at age 7 years, defined by the bottom fifth of the sex standardised height distribution.

Of those children who experienced family conflict, $31.1 \%$ were in the bottom fifth of the height distribution at age 7 years, compared with $20.2 \%$ of those who did not experience family conflict (table 1). The children who experienced family conflict were also less likely to be in the tallest height group at age 7 years: $14.4 \%$ compared with $20.9 \%$ of those who had not reported conflict by age 7 years. This relation was highly statistically significant $(\mathrm{p}<$ 0.0005). Table 2 shows that the relation between height at age 33 years and the measure of family conflict in earlier life is much weaker $(p=0.051)$. The relation remains in the same direction as for height measured in childhood, however, with $23.7 \%$ of those who experienced family conflict being in the shortest height group at age 33 years, compared with $18.9 \%$ of those who did not.

Table 3 has short stature at age 7 years (defined by the bottom fifth of the height distribution $^{6}$ ) as the outcome variable. The relative odds of being in the lowest fifth of the height distribution among those who experienced family conflict were 1.79 (95\% confidence interval (CI) 1.39 to 2.30) when compared with those who had not experienced family conflict. After adjustment for the potential confounding variables the relative odds were slightly reduced to 1.62 (95\% CI 1.18 to 2.23), indicating a relation between slow growth and family conflict which was independent of final adult height and the measures of cultural and material circumstances in childhood.

In social class $\mathrm{V}, 30.3 \%$ of children were in the short stature group, compared with $11.7 \%$ in class I, with relative odds of 3.29 (95\% CI 2.25 to 4.82). After adjustment for the potential confounding variables the strength of this relation was significantly decreased and the relative odds for short stature among children from social class $\mathrm{V}$ families were reduced to 1.45 (95\% CI 0.90 to 2.32 ) when compared with children from class I. Thus after adjustment, the relation between social class and 
Table 3. Slow growth at age 7 years indicated by the shortest fifth of the height distribution. Relative odds are adjusted for domestic conflict, social class, crowding, sex, and adult height

\begin{tabular}{|c|c|c|c|c|c|c|c|}
\hline & \multirow{2}{*}{$\begin{array}{l}\text { No (\%) of } \\
\text { children } \\
(n=6574)\end{array}$} & \multicolumn{3}{|c|}{ Unadjusted } & \multicolumn{3}{|l|}{ Adjusted } \\
\hline & & $\begin{array}{l}\text { Relative } \\
\text { odds }\end{array}$ & $95 \% C I$ & $p$ Value & $\begin{array}{l}\text { Relative } \\
\text { odds }\end{array}$ & $95 \% C I$ & $p$ Value \\
\hline Family conflict & & & & $<0.0005$ & & & 0.003 \\
\hline No & $6275(20.2)$ & 1.00 & & & 1.00 & & \\
\hline Yes & $299(31.1)$ & 1.79 & 1.39 to 2.30 & & 1.62 & 1.18 to 2.23 & \\
\hline Social class & & & & $<0.0005$ & & & 0.110 \\
\hline I & 403 (11.7) & 1.00 & & & 1.00 & & \\
\hline II & $1050(14.2)$ & 1.25 & 0.88 to 1.77 & & 1.15 & 0.76 to 1.73 & \\
\hline IIInm & $705(16.7)$ & 1.52 & 1.05 to 2.18 & & 1.29 & 0.84 to 1.98 & \\
\hline IIIm & $2943(23.5)$ & 2.32 & 1.69 to 3.19 & & 1.48 & 1.02 to 2.16 & \\
\hline IV & $1127(21.9)$ & 2.12 & 1.52 to 2.97 & & 1.25 & 0.84 to 1.88 & \\
\hline $\mathrm{V}$ & $346(30.3)$ & 3.29 & 2.25 to 4.82 & & 1.45 & 0.90 to 2.32 & \\
\hline Crowding (ppr) & & & & $<0.0005$ & & & $<0.0005$ \\
\hline Up to 1 & $4020(16.4)$ & 1.00 & & & 1.00 & & \\
\hline$\geqslant 1$ to 1.5 & $1741(22.9)$ & 1.51 & 1.31 to 1.73 & & 1.36 & 1.14 to 1.62 & \\
\hline$\geqslant 1.5$ to 2 & $631(34.9)$ & 2.72 & 2.27 to 3.27 & & 2.44 & 1.93 to 3.09 & \\
\hline$>2$ & $182(44.0)$ & 3.99 & 2.94 to 5.41 & & 3.07 & 2.08 to 4.51 & \\
\hline
\end{tabular}

$\mathrm{nm}=$ Non-manual $; \mathrm{m}=$ manual ppr $=$ person per room .

height at age 7 years was no longer statistically significant.

There was a clear gradient of association between crowding and short stature at age 7 years. A total of $44.0 \%$ of those from the most crowded households were of short stature, whereas only $16.4 \%$ of those from the least crowded households were in the shortest height fifth. The unadjusted relative odds for being in the bottom height fifth for those in the most crowded households were 3.99 (95\% CI 2.94 to 5.41) compared with those from the least crowded households. Adjustment for the potential confounding variables slightly reduced these relative odds to 3.07 (95\% CI 2.08 to 4.51).

\section{Discussion}

It has previously been observed that 7 year old boys with slowed growth are far more likely to experience later adult unemployment, even after adjustment for socioeconomic background, educational attainment, and other risk factors for unemployment. ${ }^{6}$ It is hypothesised that environmental factors, including family conflict, have dual consequences: slowing growth and also affecting psychological development. The psychological consequences of this can result in labour market disadvantage and socioeconomic adversity in adult life. Although those with slowed growth in childhood do not necessarily become the shortest adults, their poorer psychological development may result in subsequent labour market and other disadvantages. This paper has focused on psychosocial influences, in the form of family conflict, on growth rate to age 7 years. We have attempted to adjust for genetically determined height (by adjusting for fully attained adult height) and have thus focused on slowed growth.

A child's height at age 7 years is the result of the interaction between genetic and environmental influences. ${ }^{15}$ In a study of 7569 English and Scottish primary schoolchildren, Smith et al found that the socioeconomic differences in height are established in early childhood..$^{16}$ It is known, however, that only a relatively small proportion of those of short stature at age 7 years are of short stature as adults, ${ }^{17}$ indicating a significant variation in growth rates. Here, we are concerned with slowed growth to age 7 years as this may be a better indicator of environmental effects than persistent short stature. Our analysis is likely to have underestimated the influence of family conflict and socioeconomic circumstances on growth in childhood. This is because we adjusted for fully attained adult height: family conflict and socioeconomic circumstances may also result in shorter fully attained adult height. ${ }^{18}$ This 'over adjustment' was necessary to identify slowed growth rather than genetically determined short stature. The measure of family conflict used here was only taken at one time point and gave no indication of the severity or duration of exposure to conflict. As the measure of conflict was based on the health visitor's prior knowledge of the family and their use of relevant statutory and voluntary services, many cases of conflict will have remained unreported. There is likely to be a considerable amount of unobserved heterogeneity resulting in a weakening of the association between conflict and slowed growth reported here.

Family conflict before the age of 7 years had a strong and statistically significantly association with slow growth to age 7 years, even after adjustment for the potential confounding factors. The same measure of conflict was only weakly associated with fully attained adult height. Our results show independent relations of slower growth in childhood with family conflict and crowding. Lower parental social class was associated with short stature at age 7 years in the unadjusted model, but the significance of this relation was considerably reduced by adjustment for family conflict and crowding. Social class is an indicator of parental characteristics, such as level of education, as well as cultural and material circumstances in the home. The weak relation of social class with slowed growth in the adjusted model indicates that family conflict itself may influence development and that the measure of family conflict is not simply an indicator of other harmful family characteristics. Inclusion in the multivariate model of other factors known to be associated with childhood height, such as birth weight and parental smoking habits, did not 
significantly affect the relation of family conflict with height at age 7 years (data not shown). This confirms the finding from Swedish data, based only on retrospective recall, that height is related independently to economic hardship in childhood and to 'family dissension'. ${ }^{3}$ It is plausible that such influences are likely to affect emotional and physical development. These developmental consequences may themselves affect health and social mobility later in life.

The relation between household crowding and the risk of slowed growth at age 7 years is powerful and graded. This may be because crowding is a good indicator of low income and poor housing conditions and this is reflected in slower childhood growth. Frequent sleep disturbance may be another mechanism through which growth is affected in crowded households. Growth hormone is released during periods of deep sleep and its secretion rate could fall if sleep were disrupted. ${ }^{19}$ The secretion of other hormones required for normal physical development is also stimulated by growth hormone. ${ }^{20}$ Conditions that are more likely to result in disturbed sleep, such as excessive noise, shared rooms, or shared beds, could reduce growth hormone secretion and may result in slowed growth.

Family conflict during childhood has been shown to be a risk factor for subsequent psychological ill health ${ }^{21}$ and it has also been suggested that slow growth in infancy may be associated with adult depression. ${ }^{22}$ Factors affecting growth rate may influence future physical health as slow growth in infancy has been associated with an increased risk of adult coronary heart disease. ${ }^{23}$ Psychosocial stress may be responsible for these processes.

The mechanisms by which stress can influence growth and health risks are not fully understood, but basal levels of growth hormone were found to be reduced in young rhesus monkeys as a response to chronic psychological stress, probably due to a shift in the hypothalamic regulatory process. ${ }^{24}$ Possible pathways include stress induced by persistent family conflict increasing levels of the endogenous opioid, $\beta$ endorphin. ${ }^{25}$ This has been shown to modulate growth hormone release through the mediation of growth hormone releasing hormone in prepubertal children. ${ }^{26}$

The chronic childhood stress resulting from family conflict that is associated with slowed growth may have implications for future cognitive ability. Significant hippocampal degeneration has been observed in captive vervet monkeys due to increased glucocorticoid levels resulting from chronic social stress. ${ }^{27}$ If stressed children suffered hippocampal damage, then, eventually, their cognitive ability would suffer, as the hippocampus is important in learning and memory. The effect of this damage can be observed in rats, which are less able to run through mazes if there has been damage to the hippocampus. ${ }^{28}$

Stress, indicated by slow growth, could also directly increase the risk of physical illness. Studies of baboons have shown that the repeated stress response (resulting in slower

\section{Key messages}

- Stress caused by family conflict results in slow growth to age 7 years

- A higher proportion of the shortest $20 \%$ of 7 year old children have experienced psychosocial stress

- Slow growth may indicate impaired psychological development caused by stress

- Family conflict may have lifelong consequences for some children

- Slow growth may be a useful marker for psychosocial stress

human growth) significantly increases cardiovascular risk factors. ${ }^{29}$ This process may begin in childhood, but the accumulation of significant cardiovascular risk is likely to result from many years of stress. Other more immediate consequences of chronic childhood stress may be due to suppression of the immune system, increasing the risk of acute infection. ${ }^{30}$

Adverse childhood conditions may have dual risks for both poor future health and persistent socioeconomic disadvantage, which is itself a risk factor for poor health. Domestic conflict is known to be associated with a number of adverse long term developmental, physical health, psychological, ${ }^{31-33}$ and labour market ${ }^{6}$ outcomes. It may be that family conflict begins a spiral of disadvantage that results in the accumulation of health risks throughout life. A relatively high proportion of prepuberatal children in the shortest height fifth are likely to have experienced significant psychosocial adversity due to family conflict. These children are also more likely to experience socioeconomic disadvantages in adult life.

\section{Conclusions}

Slow growth in childhood is associated with family conflict and this is independent of socioeconomic circumstances. This may be because slow growth is a sensitive marker of emotional disturbance and chronic stress in childhood. The association of slow growth in childhood with labour market disadvantage in later life may be due to childhood psychosocial and material adversity resulting in adverse psychological and cognitive outcomes. Slow growth may be a useful marker for psychosocial stress.

We are grateful for assistance from the staff of the Social Statistics Research Unit, City University, London, who are responsible for the National Child Development Study.

1 Widdowson EM. Mental contentment and physical growth. Lancet 1951;i:1316-8.

2 Power C, Manor O. Asthma, enuresis, and chronic illnesslong term impact on height. Arch Dis Child 1995;73:298304 .

3 Nystrom Peck M, Lundberg O. Short stature as an effect of economic and social conditions in childhood. Soc Sci Med 1995;41:733-8.

4 Marmot MG, Shipley MJ, Rose G. Inequalities in death-specific explanations of a general pattern. Lancet
$1984 ; \mathbf{i}: 1003-6$. 
5 Marmot MG. Social inequalities in mortality: the social environment. In: Wilkinson RG, ed. Class and health

6 Montgomery SM, Bartley MJ, Cook DG, Wadsworth MEJ. Health and social precursors of unemployment in young men in Great Britain. F Epidemiol Community Health 1996; 50:415-22

7 Shepherd P. The National Child Development Study: an introduction to the background to the study and the methods of data collection. City University, London: Social Statistics Research Unit, 1985. NCDS Working Paper No 1.

8 Ferri E, ed. Life at 33. London: National Children's Bureau, 1993.

9 Butler NR, Bonham DG. Perinatal mortality. Edinburgh: Churchill Livingstone, 1963.

10 Butler NR, Alberman E D, eds. Perinatal problems. Edinburgh: Churchill Livingstone, 1969.

11 Power C, Manor O, Fox AJ. Health and class: the early years. London: Chapman and Hall, 1991.

12 Essen J, Fogelman K, Head J. Children's housing and their health and physical development. Child Health Care Dev

13 Goldblatt PO. Mortality and alternative social classifications. In: Goldblatt P, ed. Longitudinal study: mortality and social organisation. London: HMSO, 1990: 163-92.

14 Norusis MJ. SPSS user's guide. Chicago: SPSS, 1990.

15 Eveleth PB, Tanner JM. Worldwide variation in human growth. Cambridge: Cambridge University Press, 1976.

16 Smith AM, Chinn S, Rona RJ. Social factors and height gain of primary schoolchildren in England and Scotland. Ann Hum Biol 1980;7:115-24.

17 Greco L, Power C, Peckham C. Adult outcome of normal children who are short or underweight at age 7 years. $B M F$ 1995;310:696-700.

18 Peck MN, Lundberg O. Short stature as an effect of economic and social conditions in childhood. Soc Sci Med 1995;41:733-8.

19 Preece MA. Prepubertal and pubertal endocrinology. In: Falkner J, Tanner JM, eds. Human growth. 2nd Ed. Vol 2 London: Plenum Press, 1985.

20 Preece M A, Holder AT. The somatomedins: a family of serum growth factors. In: O'Riordan JLH, ed. Recent advances in endocrinology and metabolism. Vol. 2. Edinburgh: Churchill Livingstone, 1982
21 Wadsworth MEJ. Early stress and associations with adult health behaviour and parenting. In: Butler NR, Corner BD, ds. Stress and disability in childhood. Bristol: Wright, 1984: 100-4.

22 Barker DJP, Osmond C, Rodin I, Fall CHD, Winter PH. Low weight gain in infancy and suicide in adult life. $B M \mathcal{F}$ 1995;311:1203.

23 Fall CHD, Vijavakumar M, Barker DJP, Osmond C, Duggleby $S$. Weight in infancy and prevalence of coronary heart disease in adult life. BMF 1995;310:17-9.

24 Champoux M, Coe LC, Schanberg SM, Kuhn CM, Suomi SJ. Hormonal effects of early rearing conditions in the infant rhesus monkey. American fournal of Primatology 1989;19:111-7.

25 Schedlowski M, Fluge T, Richter S, Tewes U, Schmidt RE, Wagner TOF. Beta endorphin, but not substance-p, is increased by acute stress in humans. Psychomeuroendocrinot ogy 1995;20:103-10.

26 Pugliese MT, Abdenur J, Fort P, Lifshitz F. The relationship between beta-endorphin and the growth-hormone $(\mathrm{GH})$ response to $\mathrm{GH}$ releasing hormone in prepubertal children. response to $\mathrm{GH}$ releasing h

27 Uno H, Tarara R, Else JG, Suleman MA, Sapolsky RM. Hippocampal damage associated with prolonged and fatal stress in primates. $\mathcal{F}$ Neurosci $1989 ; 9: 1705-11$.

28 Meaney MJ, Aitken DK, van Berkel C, Bhatnagar S, Sapolsky RM. Effect of neonatal handling on age-related impairments associated with the hippocampus. Science 1988;239: 766-8.

29 Sapolsky RM. Endocrinology alfresco: psychoendocrine studies of wild baboons. Recent Prog Horm Res 1993;48: 437-68.

30 Cohen S, Tyrell DAJ, Smith AP. Psychological stress and susceptibility to the common cold. N Engl F Med 1991;325: 606-12.

31 Wadsworth MEJ, Maclean M, Kuh D, Rodgers B. Children of divorced and separated parents: summary and review of findings from a long-term follow-up study in the UK. Fam Pract 1990;7:104-9.

32 Wadsworth MEJ. Early stress and associations with adult health, behaviour and parenting. In: Butler NR, Corner BD, health, behaviour and parenting. In: Butler NR, Corner BD,
eds. Stress and disability in childhood. Bristol: Wright, 1984 .

33 James O. Fuvenile violence in a winner-loser culture. London: Free Association Books, 1995. 